\title{
DO FÍSICO AO VIRTUAL: RELAÇÕES INTERPESSOAIS QUE GERAM REDES SOCIAIS DOS ALUNOS DE UM CURSO DE GRADUAÇÃO
}

\author{
DE FÍSICO A VIRTUAL: RELACIONES \\ INTERPERSONALES QUE GENERAN REDES \\ SOCIALES ENTRE LOS ESTUDIANTES \\ UNIVERSITARIOS
}

Roberto Vilmar Satur - robertosatur@yahoo.com.br Doutorando em Ciência da Informação pela Universidade Federal da Paraíba (UFPB). Professora da UFPB.

Bruno de Araújo Ribeiro - brunoribeirorp@gmail.com Mestrando em Ciência da Informação pela Universidade Federal da Paraíba (UFPB).

Janecely Silveira de Lima - janecelysilveira@gmail.com Mestre em Ciência da Informação pela Universidade Federal da Paraíba (UFPB). Arquivista na Universidade Federal Rural do Semi-Árido (UFERSA).

Guilherme Ataíde Dias - guilhermeataide@gmail.com Doutor em Ciência da Informação pela Universidade de São Paulo (USP). Professor na na Universidade Federal da Paraíba (UFPB).

\section{RESUMO}

Introdução: Nos dias atuais, as redes sociais têm ocasionado uma grande participação no cotidiano das pessoas, em especial, dos estudantes, tornandose uma realidade no meio educacional. Mais do que um entretenimento, as redes vêm sendo ferramentas de interação valiosas para auxiliar na comunicação da informação.

Objetivo: Frente a esse cenário, o objetivo geral desta pesquisa é de observar a capacidade das interações interpessoais e intragrupo dos alunos de um curso de graduação (Letras Estrangeiras Aplicadas às Negociações Internacionais), de uma universidade pública (UFPB), na formação e na expansão de redes sociais iniciadas por meio de contato pessoal e ampliadas para o universo virtual. Nesse sentido, visa, especificamente, mapear as 
Roberto Vilmar Satur; Bruno de Araújo Ribeiro; Janecely Silveira de Lima; Guilherme Ataíde Dias

Do físico ao virtual: relações interpessoais que geram redes sociais dos alunos de um curso de graduação

interações interpessoais dos alunos na formação de redes sociais e na ampliação de suas relações; descrever quais as formas de interação mais utilizadas e levantar dados básicos do perfil dos atores.

Metodologia: Para conhecer bem mais essa realidade desses sujeitos, foi adotado como instrumento de coleta de dados um questionário composto por questões fechadas, direcionadas aos alunos do curso já mencionado. No total, foram listados 95 nomes de alunos no curso, no mês de maio, que podiam ser marcados pelos respondentes. A pesquisa foi aplicada durante todo o mês de junho de 2014 e computou 71 questionários respondidos. Após a coleta, lançaram-se os dados e aplicou-se o software Gephi.

Resultados: Os resultados mostram a tendência à formação de uma rede ampla no curso, porém mais intensa entre determinados alunos, formando minigrupos, e a existência de atores-ponte. $O$ artigo também demonstrou que havia uma clara passagem da relação do contato pessoal para o ambiente virtual.

Conclusões: As redes sociais podem servir de espaço de comunicação e interação, uma vez que o uso delas na educação está relacionado ao processo de ensino e aprendizagem. Portanto, há avanços nas formas de interação e de acesso e busca de informações entre os seus usuários. Assim, estudar os fenômenos que possam traduzir esse novo comportamento e essas novas interações é sobremaneira importante, tendo em vista o processo, até certo ponto irreversível, de virtualização social.

Palavras-chave: Redes sociais. Relações interpessoais. Alunos LEA. GEPHI.

\section{INTRODUÇÃO}

Em 2013, o mundo ficou perplexo com as declarações de um excolaborador da Agência de Segurança Nacional do governo americano (NSA), que declarou e, de certa forma, provou que os Estados Unidos da América (EUA) espionavam praticamente o mundo todo, sobretudo as autoridades de outros países. E o objetivo era claro: saber com quem essas autoridades conversavam, com quem tinham relações e que redes de amizade e de informações estabeleciam. Agindo assim, 0 governo estadunidense considerava que poderia antever qualquer situação que representasse alguma ameaça ao seu país ou aos interesses do povo e das empresas dos EUA. E isso era feito por meio de rastreamento e do método de análise das redes sociais (ARS). escândalo gerou grande repercussão e indignação internacional e chamou a atenção do mundo para esse tipo de ferramenta tecnológica, 
Roberto Vilmar Satur; Bruno de Araújo Ribeiro; Janecely Silveira de Lima; Guilherme Ataíde Dias

Do físico ao virtual: relações interpessoais que geram redes sociais dos alunos de um curso de graduação

com a qual é possível visualizar como as pessoas se comportam e se relacionam em rede.

Nos dias atuais, as redes sociais têm ocasionado uma grande participação no cotidiano das pessoas, em especial, nos estudantes. Essa é uma realidade no meio educacional. Mais do que entretenimento, as redes vêm sendo ferramentas de interação valiosas para auxiliar na comunicação da informação.

Fortes aliadas nas redes sociais, as tecnologias digitais de informação e comunicação (TDIC) oferecem oportunidades para criar ambientes ricos em informações e influenciar, de forma mais dinâmica, as interações. Dessa feita, as instituições educacionais, inseridas em uma conjuntura midiática, têm de instruir seus profissionais para o uso das novas ferramentas didático-pedagógicas, porque os instrumentos tecnológicos serão mais eficazes no processo de ensino-aprendizagem, quando houver qualificação e interesse relacionado ao progresso de competências, habilidades e atitudes que promovam o aproveitamento de todas as ações das tecnologias digitais, objetivando construir um elo de saber entre professor, internet, alunos e escola com ações pedagógicas.

Atualmente existem diversos dispositivos com a função de fazer circularem a informação e a comunicação. Em diversas escolas, é notável o uso frequente de tais dispositivos entre os alunos. 0 dispositivo, como técnica, diz respeito às operações realizadas, e como tecnologia, aos suportes tecnológicos, ou seja, as máquinas, os equipamentos e os instrumentos utilizados nos processos de comunicação (KLEN, 2007). Convém ressaltar que uma grande parcela da população não está incluída no mundo digital. Apesar disso, não para de crescer o número de adesões e conexões às redes sociais e à internet. Assim, a participação em comunidades virtuais tem se tornado um hábito corriqueiro.

Destaca-se, nesse contexto, a Teoria Conectivista, proposta por George Siemens em 2004, o qual apresenta um estudo teórico voltado 
Roberto Vilmar Satur; Bruno de Araújo Ribeiro; Janecely Silveira de Lima; Guilherme Ataíde Dias

Do físico ao virtual: relações interpessoais que geram redes sociais dos alunos de um curso de graduação

para a era digital. Na concepção conectivista, a aprendizagem se liga a outras ramificações como, por exemplo, a aprendizagem informal. Acontece de maneiras variadas - através de comunidades de prática, de redes pessoais (interação) e da conclusão de tarefas relacionadas ao trabalho (SIEMENS, 2011).

Os artefatos tecnológicos digitais, com destaque, hoje, para os aparelhos móveis, potencializam as práticas pedagógicas. Para isso, é necessário mudar paradigmas e abrir caminho para o uso das mídias sociais na escola, ou seja, edificar um olhar para o que antes não era visto como dispositivo de aprendizagem (AMARAL; BEHAR; DORNELLES, 2011).

\subsection{Objetivo e Questão da Pesquisa}

Este artigo objetiva analisar comportamentos e relações interpessoais entre jovens estudantes de um curso para verificar como eles estabelecem suas redes sociais entre seus pares. Para isso, utilizase um dos softwares disponíveis para aplicar o método de ARS.

Assim, desenvolveu-se a seguinte questão de pesquisa: De que forma as interações interpessoais e intragrupo de estudantes de um curso universitário, iniciadas pelo contato pessoal, expandem-se para o universo virtual intensificando essas relações, fortalecendo e consolidando esse grupo como rede social?

Frente a esse cenário, o objetivo geral desta pesquisa é de observar a capacidade das interações interpessoais e intragrupo dos alunos de um curso de graduação, de uma universidade pública, na formação e na expansão de redes sociais iniciadas por meio de contato pessoal e ampliadas para o universo virtual. Nesse sentido, visa, especificamente, mapear as interações interpessoais dos alunos na formação de redes sociais e na ampliação de suas relações; descrever quais as formas de interação mais utilizadas e levantar dados básicos do perfil dos atores. 
Roberto Vilmar Satur; Bruno de Araújo Ribeiro; Janecely Silveira de Lima; Guilherme Ataíde Dias

Do físico ao virtual: relações interpessoais que geram redes sociais dos alunos de um curso de graduação

\section{REDES SOCIAIS: PRESSUPOSTOS TEÓRICOS}

Neste capítulo, apresentam-se as discussões sobre redes sociais e sua análise.

\subsection{As Redes Sociais e seus Desdobramentos}

Apesar de muitos acharem que o tema rede social foi criado na atualidade, somente o novo formato de rede, baseado em computador e em internet, é recente. Afinal, todo convívio em comunidade, grupo ou família constitui uma rede social. Assim, os estudos sobre redes sociais não são tão recentes.

Pinheiro (2012), utilizando-se dos argumentos de Mendes (2005), cita o ano de 1735 como o marco inicial dos estudos de redes. Foi Leonard Euler quem fez o famoso estudo do problema das pontes de Königsberg, considerado o ponto inicial dos estudos matemáticos que ficou conhecido como a Teoria dos Grafos. Nessa teoria, destacam-se as contribuições de Erdos Rényi, além de trabalhos precursores de Milgram (1967). Nas últimas décadas, com o surgimento das redes virtuais e o aumento da capacidade computacional para cálculos, foi possível melhorar sobremaneira o volume de tais estudos.

Barabási (2012) afirma que o emprego da palavra rede se intensificou a contar da década de 1980. Trata-se de uma palavra com muitos usos e aplicações, principalmente para explicar e entender as relações em redes na sociedade. $O$ uso da rede pelas ciências oferece novas ferramentas e perspectivas para uma ampla gama de campos científicos por meio de redes sociais. Quando se entendem a importância e o impacto das redes, está-se buscando desenvolver ferramentas para estudá-la e quantificá-la.

Em qualquer lugar e em qualquer grupo, podem-se formar redes, formais ou informais. Tswetovat e Kouznetov (2011), na parte inicial de seu livro, fazem uma abordagem das várias formas de rede social dando 
Roberto Vilmar Satur; Bruno de Araújo Ribeiro; Janecely Silveira de Lima; Guilherme Ataíde Dias

Do físico ao virtual: relações interpessoais que geram redes sociais dos alunos de um curso de graduação

ênfase à capacidade de se formarem redes sociais informais até em situações extremamente adversas, apesar de todos os esforços que alguém possa fazer para preveni-la. Para exemplificar isso, os autores (TSWETOVAT; KOUZNETOV, 2011) mencionam situações de formação de redes em presídios onde, que apesar da dificuldade decorrente de certo isolamento, existe o correio intraprisão, com mensagens ou encomendas que passam de cela em cela até chegar ao seu destinatário. Quando as autoridades localizam e destroem esse canal de comunicação e de passagem, em questão de tempo, encontra-se outra forma de rede ou novo canal que entra em operação.

As redes podem ser desde as mais simples (família, amigos próximos) até as mais complexas. Segundo Albert e Barabási (2002), as redes complexas descrevem uma ampla gama de sistemas na natureza e na sociedade. Como exemplo, podem ser citadas as células e a Internet. Normalmente, nessas relações em rede, sempre existirão atores que se destacam e servirão de referência (ponte) para fazer a ligação, por exemplo, entre dois grupos (MATHEUS; SILVA, 2009, p. 244-245).

Granovetter (1973) vai além e destaca sua importância para os laços fracos, especialmente porque eles fazem ligações entre grupos diversos e propagam rapidamente a interação. Enquanto os laços fortes fortalecem as relações entre alguns atores, os fracos é que mantêm a relação conectada com atores que estariam distantes ou não conectados com esse ator ou grupo se isso dependesse do laço forte. Grosser (1991) também concorda com esse pensamento e fala que esse ator tem laços fracos com muitos grupos de atores-ponte. Trata-se do ator de um grupo que interage com outros dos demais grupos e promove a interação entre grupos ou subgrupos (GROSSER, 1991).

Tswetovat e Kouznetov (2011) exemplificam essa questão do ator com o caso da formação de redes informais em células terroristas. Eles referem que o serviço de inteligência do governo eliminava determinado membro-chave da comunicação e da interligação das redes. Isso 
Roberto Vilmar Satur; Bruno de Araújo Ribeiro; Janecely Silveira de Lima; Guilherme Ataíde Dias

Do físico ao virtual: relações interpessoais que geram redes sociais dos alunos de um curso de graduação

causava certa perturbação inicial, mas logo se restabelecia com outro membro da rede assumindo a função do que fora eliminado. "A rede se adapta e é continuamente otimizada para a confiabilidade". A comunicação pessoal, o boca a boca, nesses casos, funciona perfeitamente.

Para Granovetter (1973, p.1361), das relações resultam ligações fortes ou fracas, que normalmente se estabelecem em rede. $E$ complementa: "the strength of a tie is a (probably linear) combination of the amount of time, the emotional intensity, the intimacy (mutual confiding), and the reciprocal services which characterize the tie." Significa dizer que o tempo, a emoção, a confiança entre as partes e os favores e os serviços recíprocos entre as partes dirão se os laços que se estabelecerão serão fortes ou fracos.

Barabási e Bonabeau (2003), ao definir e exemplificar redes, afirmam que o cérebro pode ser considerado uma rede de células nervosas conectadas, enquanto as células em si são redes de moléculas ligadas por reações bioquímicas. As sociedades também são redes de pessoas que se ligam por amizades e relações profissionais e pessoais. Ainda em escala mais agregada, os autores citam as teias alimentares e o ecossistema como redes de espécies e finalizam mencionando as redes permeadas por tecnologia, especialmente a Internet, as redes de transmissão de energia e de comunicação e o sistema de transporte e de logística. Até a linguagem que empregamos na comunicação é uma rede feita de palavras ligadas por relações sintáticas por meio das quais podemos transmitir nossos pensamentos para outros.

A rede social pode tomar proporções gigantescas, especialmente quando auxiliada pelos meios mediáticos. Os autores citam o caso da Primavera Árabe, em 2011, e os movimentos anteriores, como o da Moldávia, em 2009, e o levante iraniano suprimido pelas autoridades. Convém citar, ainda, o movimento ocorrido no Brasil, em 2013, que começou como o Movimento Passe Livre, mas que poderia ser chamado 
Roberto Vilmar Satur; Bruno de Araújo Ribeiro; Janecely Silveira de Lima; Guilherme Ataíde Dias

Do físico ao virtual: relações interpessoais que geram redes sociais dos alunos de um curso de graduação

de "Inverno Facebook, e que os autores não citaram por terem publicado o livro antes. Eles perguntam como as redes sociais se tornam tão poderosas, quando a internet passa a ser o veículo comunicacional, e respondem que isso é decorrente da capacidade que as mídias têm de transformar laços fracos em fortes de um momento para outro e de fazer conexões inúmeras entre pessoas com pouco ou nenhum apego afetivo ou emocional. Além disso, não exigem obrigatoriedade presencial nem hora marcada, são gratuitas, podem ter adesão ou desistência a qualquer momento e permitem que as pessoas sejam descompromissadas se quiserem. Assim, pessoas da mesma rede podem ter opiniões totalmente diferentes sobre a mesma coisa sem que isso leve ao conflito. Além disso, a qualquer momento, um anônimo, que lá está, pode levar como prêmio a passagem repentina do anonimato para a celebridade (os chamados "15 minutos de fama") (TSWETOVAT; KOUZNETOV, 2011).

Quanto às redes baseadas na internet, Clara (2013, p. 3) afirma que, "na relação entre as tecnologias digitais e as humanidades, as tecnologias computacionais são, ao mesmo tempo, 'ferramentas úteis' na construção do conhecimento e determinantes da construção do conhecimento". A formação de redes pela internet amplia a atuação, especialmente, em velocidade de circulação de informação e no fim do espaço geográfico como barreira.

Com a rede, um cidadão pode publicar algo que é replicado ou compartilhado com todos os membros de sua rede, que têm sua própria rede e que também podem replicar, e assim sucessivamente. Dessa forma, num curto espaço de tempo, as dimensões e o alcance dessa informação passam a ser grandiosos. Quando se tem a capacidade de rastrear esse tipo de informação, é possível, por exemplo, prever sua dimensão e alcançá-la, saber quem a compartilhou e com quem e alcançar as relações. (TSWETOVAT; KOUZNETOV, 2011).

Sobre os tipos de redes sociais, Pinheiro (2012) afirma: 
Roberto Vilmar Satur; Bruno de Araújo Ribeiro; Janecely Silveira de Lima; Guilherme Ataíde Dias

Do físico ao virtual: relações interpessoais que geram redes sociais dos alunos de um curso de graduação

A classificação mais abrangente está referenciada à sua natureza: redes aleatórias e redes reais. As redes são classificadas também se levando em consideração a variação ou não dos tipos de nodos ou vértices, podendo apresentar nodos de naturezas diferentes, ou nodos de natureza única. Quanto às ligações ou arestas, as redes podem apresentar direcionamentos de ligações ou ligações não direcionadas. O tipo mais simples de rede é o que apresenta uma única natureza de nodos e ligações não direcionadas. A intensidade das ligações que representam a frequência de relações entre os nodos também é um parâmetro considerado para a tipologia da rede (PINHEIRO, 2012, p. 198).

As redes sociais também podem ser classificadas, quanto a sua topologia, em: redes igualitárias, redes mundos pequenos e redes sem escala.

Sobre as redes igualitárias, Recuero (2009, p. 58-59) assevera:

\begin{abstract}
Um dos trabalhos associados geralmente com essa proposta da teoria das redes é o estudo dos grafos aleatórios de Solomonoff e Rapoport (1951). [...] Em seu trabalho, os autores demonstraram que as propriedades dos grafos randômicos surgiriam de modo súbito, quando os novos vértices são acrescentados ao grafo. [...]. Erdös e Rényi, normalmente citados como os criadores do modelo [...], demonstraram que as propriedades dos grafos randômicos surgiriam de modo súbito, quando os novos vértices são acrescentados ao grafo. Entretanto, como esses nós se conectariam, ou ainda, como essas arestas apareceriam? Erdös e Rényi (1960) acreditavam que o processo de formação dos grafos era randômico, no sentido de que esses nós se agregavam aleatoriamente. Dessa premissa, eles concluíram que todos os nós, em uma determinada rede, deveriam ter mais ou menos a mesma quantidade de conexões, ou igualdade nas chances de receber novos links, constituindo-se, assim, como redes igualitárias (BARABÁSI, 2003, p.9-24). Em uma rede igualitária, os nós teriam mais ou menos a mesma quantidade de conexões.
\end{abstract}

Quanto às redes mundos pequenos, Recuero (2009) destaca Ithiel de Sola Pool e Manfred Kochen (1978). A expressão popular "que mundo pequeno" remete a uma analogia sobre determinada pessoa que conhece alguém que conhece outrem, ou encontra um conhecido em um lugar que não imaginava que encontraria. 
Roberto Vilmar Satur; Bruno de Araújo Ribeiro; Janecely Silveira de Lima; Guilherme Ataíde Dias

Do físico ao virtual: relações interpessoais que geram redes sociais dos alunos de um curso de graduação

Neste trabalho, os autores levantaram, pela primeira vez, o problema dos "mundos pequenos", além de questões voltadas para a amizade e as conexões sociais. O problema dos mundos pequenos, que foi abordado por diversos autores posteriores, observa a questão das coincidências entre conhecidos. Trata-se de um problema de conectividade, onde os autores propuseram que, dado um número de mil conhecidos por pessoa, em toda a população mundial, poderse-ia traçar um caminho entre um par, correndo apenas por dois conhecidos de ambos. (RECUERO, 2009, p. 60).

Esses dados são comprados em pesquisas feitas pelo sociólogo Stanley Milgram (1956), que enviou cartas de forma aleatória para determinadas pessoas, e depois, junto com Jeffrey Travers (1969), enviou pacotes para certo destinatário. A lógica era mandar para uma pessoa, e quem a recebesse deveria registrar que recebeu e, desse encaminhamento, enviaria a quem imaginava que conhecia essa pessoa, até chegar à destinada efetivamente. Chegou a seis o grau de separação entre os pares, nos Estados Unidos, e depois, estendido para todo o planeta (RECUERO, 2009).

Sobre o quesito redes sem escala, convém destacar outro apontamento de Recuero (2009, p. 65):

Em 1999, utilizando um crawler para estudar as conexões na Web, Albert-Lazlo Barabási descobriu que havia um grau de conexão diferente do esperado. Embora a maior parte da rede possuísse um grau de conexão mais ou menos estável, havia alguns nós com um número altíssimo de arestas (Barabási \& Albert, 1999). Os autores identificaram, assim, uma proporção de $80 / 20$, onde $20 \%$ dos nós concentrariam $80 \%$ das conexões.

Essa proporção tem a mesma conotação da Curva $A B C$ que é utilizada com frequência na Ciência da Administração para explicar a lógica de estoque de materiais e a força de venda. Sempre existem os $20 \%$ mais importantes (vitais) e os $80 \%$ menos relevantes, mas necessários (triviais), ou a chamada Curva de Lorenz, que explica a desigualdade da distribuição da renda, em que $20 \%$ da população detêm $80 \%$ da renda, e $80 \%$ ficam com $20 \%$. 
Roberto Vilmar Satur; Bruno de Araújo Ribeiro; Janecely Silveira de Lima; Guilherme Ataíde Dias

Do físico ao virtual: relações interpessoais que geram redes sociais dos alunos de um curso de graduação

A identificação desse padrão em variados tipos de rede [...] é que deu origem ao estudo das redes sem escalas, através da lei de potência (power law) (Newman, Barabási \& Watts, 2006). A distribuição que segue uma lei de potência foi uma novidade, pois não era abarcada pelos modelos anteriores [...] O primeiro problema da teoria dos mundos pequenos de Watts foi apontado por Barabási (2003) pouco tempo após a publicação do trabalho. Watts tratava as suas redes sociais como redes aleatórias [...]Barabási e Albert (1999) demonstraram que as redes não eram formadas de modo aleatório. Eles demonstraram que, como os estudos de Watts e Strogatz, bem como de Granovetter, tinham apontado sem que os próprios autores se dessem conta, existia uma ordem na dinâmica de estruturação das redes, no seu crescimento. Essa lei, ou padrão de estruturação, foi chamada pelos autores de "rich get richer" - ricos ficam mais ricos. Ou seja, quanto mais conexões um nó possui, maiores as chances de ele ter mais novas conexões. Ele chamou essa característica de preferential attachment ou conexão preferencial: um novo nó tende a se conectar com um nó preexistente, mas mais conectado. Essa assertiva implica outra premissa fundamental: as redes não seriam constituídas de nós igualitários, ou seja, com a possibilidade de ter, mais ou menos, o mesmo número de conexões. Ao contrário, tais redes possuiriam nós que seriam altamente conectados (hubs ou conectores) e uma grande maioria de nós com poucas conexões (RECUERO, 2009, p. 65-67).

Assim, como toda organização e as relações sociais, as redes sociais têm certa lógica de organização e desenvolvimento. Cada uma delas tem razões para estar formada assim, e só se consegue ver o motivo por que isso ocorre se elas forem analisadas.

\subsection{Análise das Redes Sociais}

A Ciência da Informação tem evoluído na capacidade de contribuir com a sociedade, com mecanismos que aprofundem 0 entendimento e deem respostas melhores sobre como se comportam os atores e a sociedade atual. O estudo das informações e seu fluxo em redes interpessoais é cada vez maior e acontece, principalmente, através da análise das redes sociais. Como afirmam Matheus e Silva (2009, p. 282), 
Roberto Vilmar Satur; Bruno de Araújo Ribeiro; Janecely Silveira de Lima; Guilherme Ataíde Dias

Do físico ao virtual: relações interpessoais que geram redes sociais dos alunos de um curso de graduação

[...] considerando que o estudo dos fluxos de informação, em geral, e da comunicação e da produção científica, em particular, são importantes para a sociedade como um todo, e ainda a presença de artigos que adotam a ARS em revistas de grande impacto científico, como a Science e a Nature, o momento parece indicar uma oportunidade para os pesquisadores da $\mathrm{Cl}$.

Para a questão da análise das redes sociais, é importante considerar o que define Pinheiro (2012, p. 196) sobre redes: "A rede ou grafo, termo mais utilizado na literatura matemática, é um conjunto de vértices interligados. Os vértices são denominados nodos e as ligações são denominadas arestas".

Segundo Wasserman e Faust (1994), a análise de redes sociais é um método utilizado com frequência, especialmente nas Ciências Sociais e Comportamentais, na Economia, no Marketing e na Engenharia. Ela foca as relações entre entidades sociais e entre pessoas e tenta verificar os atributos das unidades sociais. As relações se estabelecem e criam vínculos considerando que "laços relacionais (vínculos) entre os atores são canais para a transferência ou "fluxo" de recursos (materiais ou imateriais)" (WASSERMAN; FAUST, 1994, p. 4).

Matheus e Silva (2009, p. 243-244), segundo a lógica dos autores citados, resumiram os tipos mais comuns de laços: o individual ou pessoal (amizade, parentesco ou por respeito); as trocas materiais (compra e venda, parcerias, favores); as trocas imateriais (mensagem eletrônica, informações) e a associação ou afiliação (participação em atividades afins ou em comum, como: entidades, clubes, eventos, estudos, emprego, hobby). Os laços ainda podem ser formais (com chefes, trabalho, autoridades) ou informais (amigos, colegas, familiares e outros).

Wasserman e Faust (1994, p. 247) referem que a relação em uma rede é resultado dos "relacionamentos e das funções que as pessoas têm em virtude de ocupar um status social particular". Matheus e Silva (2009, p. 245), também inspirados nesses autores, entendem que a relação leva em conta o conjunto de laços que têm o mesmo critério de 
Roberto Vilmar Satur; Bruno de Araújo Ribeiro; Janecely Silveira de Lima; Guilherme Ataíde Dias

Do físico ao virtual: relações interpessoais que geram redes sociais dos alunos de um curso de graduação

relacionamento em um conjunto de atores e em que as redes multirrelacionais são as que têm mais de um tipo de laço, mais de uma relação. Nessas relações, duas propriedades importantes devem ser consideradas: 1) o direcionamento, que envolve os direcionais - quando um ator transmite, e outro apenas recebe - e os não direcionais - quando há reciprocidade; e; 2) valoração: que pode ser dicotômica, em que, se há relação, o valor é 1 , e se não há, o valor é 0 (zero), ou valorada com valores discretos ou contínuos. Por exemplo: a valoração pode ser pela quantidade de contato ou pelas formas de contatos com que se faz a relação.

Pinheiro (2012, p. 198) assevera que, "para a análise de uma rede, são necessárias as definições prévias das representações dos nodos e dos tipos de ligações que farão parte da composição do grafo da rede". De posse dessas premissas, é possível iniciar os trabalhos pelo método de ARS e o recomendável é o uso de software especializado, divido à complexidade desses dados e informações.

\section{METODOLOGIA}

Este artigo decorre de uma pesquisa realizada no mês de junho de 2014, onde fora realizada uma pesquisa de acompanhamento no processo de interações estabelecidas entre os alunos regularmente matriculados no curso. A interação ocorreu através do uso das redes sociais, observando-se a relação entre os alunos das quatro turmas de um curso que tem oito semestres de duração e entrada anual.

Para conseguir os dados e as informações pertinentes a este estudo, optamos pela coleta de dados:

Chamamos de "coleta de dados" a fase do método de pesquisa, cujo objetivo é obter informações da realidade. Nessa etapa, definimos onde e como será realizada a pesquisa. Será definido o tipo de pesquisa, a população (universo da pesquisa), a amostragem, os instrumentos de coleta de dados e a forma como pretendemos tabular e 
Roberto Vilmar Satur; Bruno de Araújo Ribeiro; Janecely Silveira de Lima; Guilherme Ataíde Dias

Do físico ao virtual: relações interpessoais que geram redes sociais dos alunos de um curso de graduação

analisar seus dados. É a fase da pesquisa em que reunimos dados através de técnicas específicas (PRODANOV; FREITAS, 2013, p. 97).

Como forma de conhecer os alunos pesquisados de um modo mais geral, o instrumento de coleta de dados aplicado foi um questionário composto por questões fechadas, direcionadas aos alunos do curso já mencionado. As questões buscavam investigar características qualitativas e quantitativas da relação de interação com as pessoas listadas. As perguntas foram elaboradas para ser compreendidas com facilidade.

No total, como população e amostra, foram listados 95 nomes de alunos matriculados no final de maio de 2014 no referido curso. A ideia original era observar o total da população como universo pesquisado. No entanto, no decorrer do mês de junho, enquanto se aplicavam os questionários, houve desistências e trancamentos do semestre de alunos, por motivos diversos, o que reduziu o número de alunos aptos a responder o referido questionário. No final, o total de respondentes foi de 71 alunos.

A pesquisa é exploratória e descritiva, de caráter quantitativo e qualitativo. Para a compilação dos dados, foi utilizado o software GEPHI, na formação das redes sociais e na elaboração de grafos para análise. O método de análise das redes sociais (ARS) contribui nesse sentido.

\subsection{O Software Gephi}

Existem diversos softwares que permitem a análise das redes sociais por meio de grafos e visualização de redes. Entre eles, destacam-se o UCINET, o PAJEK, o NODEXL e o GEPHI. Este último foi o escolhido para visualizar as redes sociais que se formaram neste estudo com a compilação dos dados.

Segundo Clara (2013), os softwares de análise de redes sociais oferecem novas formas de visualizar as informações, especialmente nas humanidades digitais ou qualquer outra forma de rede com certa 
Roberto Vilmar Satur; Bruno de Araújo Ribeiro; Janecely Silveira de Lima; Guilherme Ataíde Dias

Do físico ao virtual: relações interpessoais que geram redes sociais dos alunos de um curso de graduação

complexidade, e manipular dados históricos, espaciais e textuais. Porém os que mais se destacam são aqueles em que se usam grafos para visualizar as redes. A autora acrescenta que "a ferramenta para manipulação de grafos mais utilizada tem sido o GEPHI, um software livre colaborativo, mantido por um consórcio sediado na França, com inúmeras aplicações em áreas como as Ciências Biológicas ou a Economia". Aqui comentamos sua utilização em projetos ligados à história e à análise textual (CLARA, 2013, p. 1).

Segundo, ainda, a autora, um dos primeiros projetos em que se usou o GHEPI foi o Mapa da "República das Letras" (Maping the Republic of Letters), da Universidade de Stanford, dedicado às redes formadas mediante trocas de correspondência entre intelectuais (letrados) dos Séculos XVII e XVIII e envolveu 55 mil cartas e 6,4 mil correspondentes (CLARA, 2013).

Figura 1 - Cartografia de "Mapping the Republic of Letters": visualização de conexões

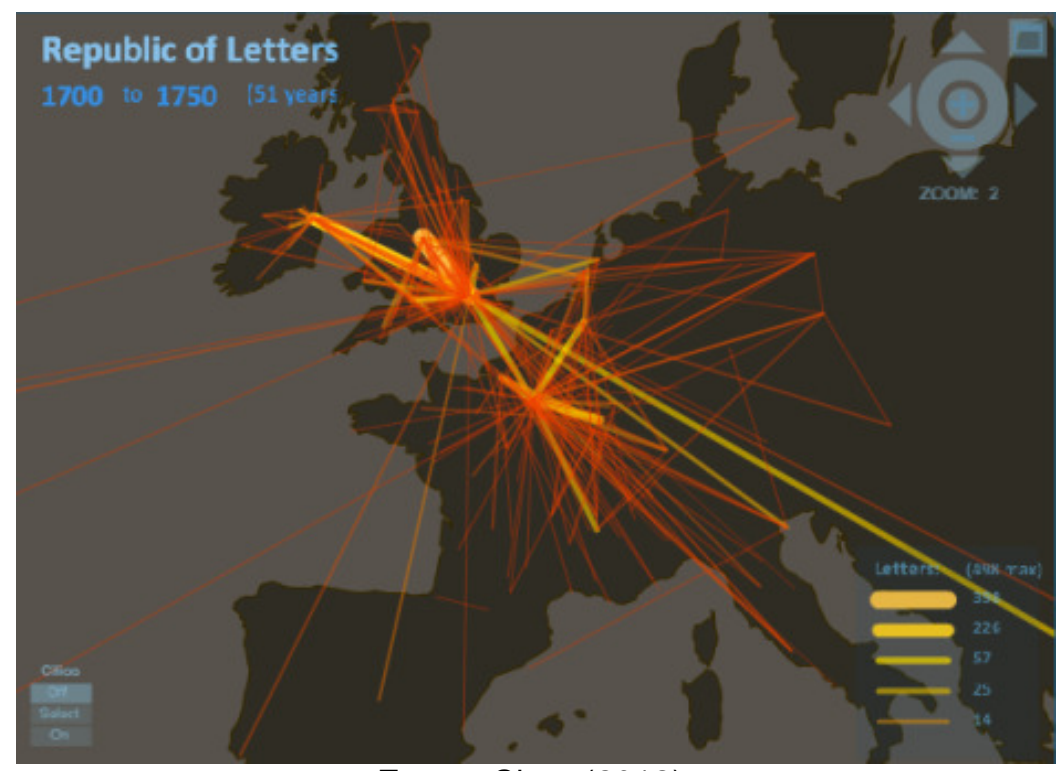

Fonte: Clara (2013).

Para Bastian, Heyamann e Jacomy (2014), o Gephi é um software de código aberto para análise gráfica de redes sociais ou afins. Para isso, utiliza um mecanismo que permite visualização $3 \mathrm{D}$, de 
Roberto Vilmar Satur; Bruno de Araújo Ribeiro; Janecely Silveira de Lima; Guilherme Ataíde Dias

Do físico ao virtual: relações interpessoais que geram redes sociais dos alunos de um curso de graduação

arquitetura flexível e multitarefa para trabalhar com um conjunto de dados complexos, que aceleram a exploração e a exibição de grandes redes em tempo real, além de pesquisa interativa, interpretação de redes. Também é possível filtrar, especializar, manipular e analisar clusters. ${ }^{1}$ É um software por meio do qual se conseguem estudar grandes redes (ou seja, mais de 20.000 nós) e executar vários algoritmos ao mesmo tempo, em espaços de trabalho separados, sem bloqueios, que o conjunto de nós ou arestas possa ser obtido manualmente ou por sistema de filtro e que os arquivos vetoriais sejam compartilhados ou impressos. Ou seja, o GEPHI foi desenvolvido para apoiar todo o processo de análise de redes sociais e ser manipulado pela interface com o seu usuário.

Ainda sobre o Gephi, Pinheiro (2012, p. 107-108) acrescenta:

O software Gephi apresenta três interfaces gerais. A primeira é a visão geral, que exibe na mesma janela as principais seções de trabalho partição, classificação, grafo e tabela de dados. A tabela de dados exibe os dados dos nodos e ligações, bem como as frequências de relações. A classificação possibilita a associação de cores com intensidades variadas para demonstrar o peso das relações. O grafo exibe as relações entre os nodos com os direcionamentos das ligações, representando a intensidade das ligações, a partir da espessura das linhas que os interligam. A tabela de dados exibe os dados importados ou digitados no próprio software para a geração da rede, possibilitando edição e ajustes. [...] A segunda interface é $o$ laboratório de dados, que permite a manipulação dos dados referentes aos nodos e às ligações, possibilitando também a importação e exportação de dados. A terceira interface é a de visualização, em cuja área é possível configurar a visualização, escolhendo parâmetros para os nós, rótulos dos nós, arestas e setas das arestas. Outro módulo muito importante para a pesquisa foi o módulo de estatísticas. Esse módulo calcula automaticamente os parâmetros principais da rede, possibilitando a análise da rede e composições de indicadores para utilização como parâmetros de outras

1 Clusters são grupos de nós bem conectados. Em termos de redes sociais, os clusters são considerados grupos sociais coesos. Eles são unidos a outros grupos através de laços individuais de seus membros.

<http://webcache.googleusercontent.com/search?q=cache:e2qQ2Hq3sAJ>. $<$ www.ufrgs.br/limc/PDFs/redes_sociais.pdf+\&cd=2\&hl=pt-BR\&ct=clnk\&gl=br $>$ 
Roberto Vilmar Satur; Bruno de Araújo Ribeiro; Janecely Silveira de Lima; Guilherme Ataíde Dias

Do físico ao virtual: relações interpessoais que geram redes sociais dos alunos de um curso de graduação

análises. Os parâmetros gerados pelo módulo de estatísticas [...] são: grau médio, grau ponderado médio, diâmetro da rede, densidade do grafo, comprimento médio de caminho.

Com o uso de um software de grafos, neste caso, o GEPHI, objetiva-se contribuir para que os leitores tenham mais facilidade de entender os dados aplicados em gráficos, utilizando símbolos que sejam simples e fáceis de distinguir. É um software que está escrito em Java, considerado como "photoshop para grafos" e que tem como característica a interatividade $\mathrm{O}$ seu manuseio é bem prático e fácil, assim como a exploração e a visualização de grafos dinâmicos e hierárquicos e de todos os tipos de redes e sistemas complexos.

\section{RESULTADOS: DEMONSTRAÇÕES, ANÁLISES E DISCUSSÕES}

Nesse ponto, o objetivo principal é de fazer uma breve análise dos dados obtidos através da pesquisa, uma vez que eles serão discutidos com mais detalhes no próximo ponto. Serão usados tabelas, figuras e "grafos" obtidos pelo software GEPHI e apresentado o perfil geral dos alunos envolvidos na aplicação do questionário na Tabela 1.

Tabela 1 - Perfil geral dos estudantes pesquisados

\begin{tabular}{|c|c|c|c|c|c|c|c|c|c|c|c|}
\hline Sexo & Quant. & $\%$ & Est.Civil & Quant. & $\%$ & Idade & Quant. & $\%$ & Origem & Quant. & $\%$ \\
\hline Feminino & 41 & $57,7 \%$ & Solteiro & 66 & $93,0 \%$ & Até 17 anos & 5 & $7,0 \%$ & Paraíba & 40 & $56,3 \%$ \\
\hline \multirow[t]{12}{*}{ Masculino } & 30 & $42,3 \%$ & Casado & 3 & $4,2 \%$ & De 17 a 20 anos & 25 & $35,2 \%$ & Pernambuco & 13 & $18,3 \%$ \\
\hline & & & Outro & 2 & $2,8 \%$ & De 20 a 25 anos & 33 & $46,5 \%$ & Rio Grande do Norte & 3 & $4,2 \%$ \\
\hline & & & & & & Acima de 25 anos & 8 & $11,3 \%$ & São Paulo & 3 & $4,2 \%$ \\
\hline & & & & & & & & & Ceará & 2 & $2,8 \%$ \\
\hline & & & & & & & & & Minas Gerais & 2 & $2,8 \%$ \\
\hline & & & & & & & & & Bahia & 2 & $2,8 \%$ \\
\hline & & & & & & & & & Maranhão & 1 & $1,4 \%$ \\
\hline & & & & & & & & & Amazonas & 1 & $1,4 \%$ \\
\hline & & & & & & & & & Tocantins & 1 & $1,4 \%$ \\
\hline & & & & & & & & & Pará & 1 & $1,4 \%$ \\
\hline & & & & & & & & & Amapá & 1 & $1,4 \%$ \\
\hline & & & & & & & & & Não se Id. & 1 & $1,4 \%$ \\
\hline Total & 71 & $100 \%$ & Total & 71 & $100 \%$ & Total & 71 & $100 \%$ & Total & 71 & $100 \%$ \\
\hline
\end{tabular}

Fonte: Resultado da pesquisa (os autores) 
Roberto Vilmar Satur; Bruno de Araújo Ribeiro; Janecely Silveira de Lima; Guilherme Ataíde Dias

Do físico ao virtual: relações interpessoais que geram redes sociais dos alunos de um curso de graduação

No perfil dos alunos do curso LEA, é notável que a maioria dos entrevistados é de mulheres com idades entre 20 e 25 anos, solteiras e naturais da Paraíba. No entanto, é inegável a grande presença de estudantes de outras idades e de outros locais, conforme pode ser visualizado na Tabela 01.

Na Figura 2, vê-se que o gráfico apresenta as formas de relações intragrupo que mais se destacaram entre os alunos pesquisados.

Figura 2 - Gráfico das formas de relações interpessoais e comunicações utilizadas pelos estudantes

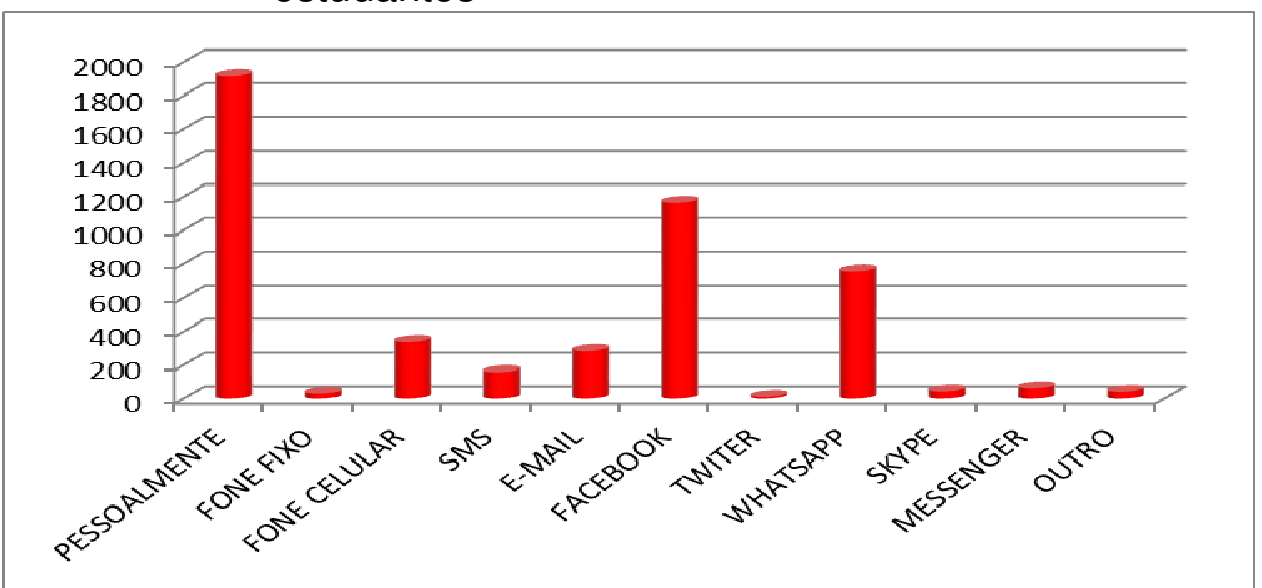

Fonte: Resultado da pesquisa (os autores)

As redes sociais aqui apresentadas podem ser denominadas de mundo pequeno, considerando que se trata de alunos de determinado curso específico. Por essa razão, convém deixar claro que, embora alguns alunos não conheçam os colegas de outros períodos do curso, eles conheciam outros que certamente já faziam parte do convívio dos conhecidos.

Outro detalhe relevante da pesquisa é que o contato pessoal, efetivamente, é o grande responsável pelo fato de os alunos conhecerem uns aos outros, afinal, de 1.984 relações detectadas entre estudantes, 1.916 tinham o componente "pessoalmente", o que significa $96,57 \%$ dos casos. Isso responde parte da pergunta de pesquisa, pois demonstra que o componente 'contato pessoal' é que realmente inicia 
Roberto Vilmar Satur; Bruno de Araújo Ribeiro; Janecely Silveira de Lima; Guilherme Ataíde Dias

Do físico ao virtual: relações interpessoais que geram redes sociais dos alunos de um curso de graduação

as relações da rede social do curso. Também confirma que tais relações se expandem para o ambiente virtual das redes sociais, tendo em vista que isso gerou outras 2.890 formas de relações virtuais em rede entre os alunos, totalizando 4.806 formas de relações entre os 71 estudantes pesquisados e do universo de 95 alunos que podem ser registrados como os que se relacionam, o que gera uma média de 67,7 formas de relações estabelecidas com seus colegas, por aluno.

Quanto aos meios de estabelecer conexões com os colegas (Figura 02), destacam-se o contato pessoal, o Facebook e o Whatsapp. Chama a atenção o baixo desempenho, por exemplo, de ferramentas até então tradicionais ou conhecidas, como telefone, correio eletrônico, Twitter e Skype. Essa seria uma tendência dos estudantes, que podem influenciar para a comodidade, o acesso, a tendência ou o custo.

$\mathrm{Na}$ figura abaixo, estão explícitos os resultados das conexões entre esses estudantes estruturados em rede, onde nós com mais visibilidade (tamanho) significam mais conexões.

Figura 3 - Demonstração da distribuição das conexões entre estudantes

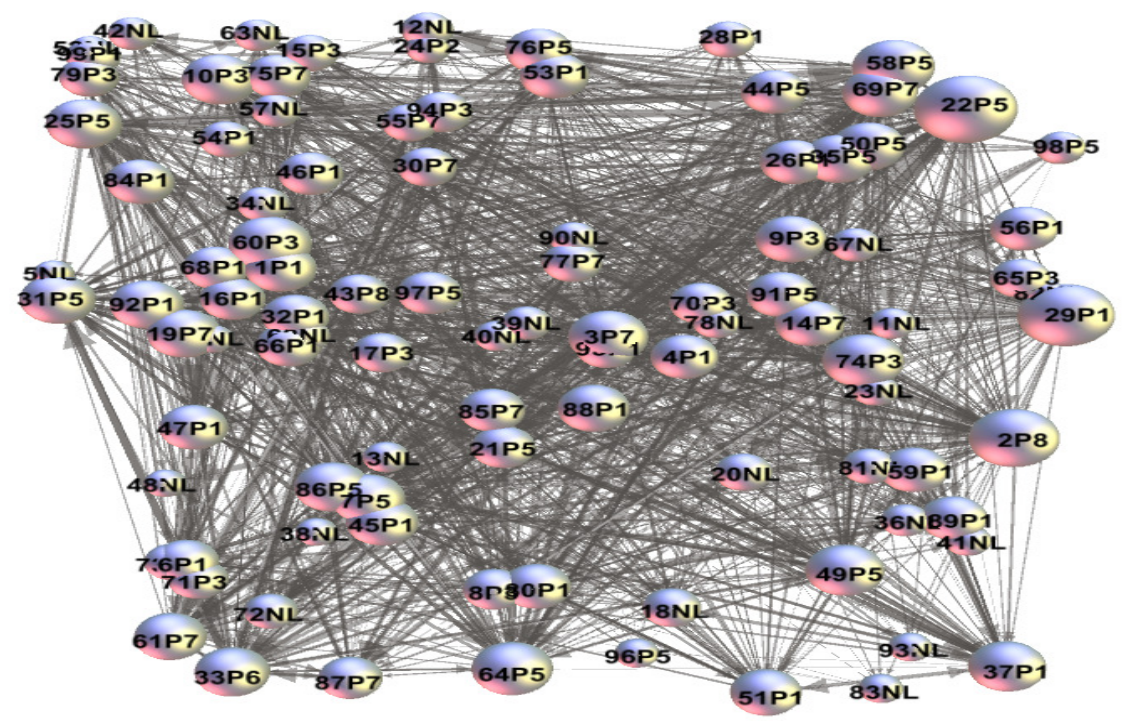

Fonte: Resultado da pesquisa (os autores)

Inf. Inf., Londrina, v. 20, n. 3, p. 05 - 38, set./dez. 2015.

http:www.uel.br/revistas/informacao/ 
Roberto Vilmar Satur; Bruno de Araújo Ribeiro; Janecely Silveira de Lima; Guilherme Ataíde Dias

Do físico ao virtual: relações interpessoais que geram redes sociais dos alunos de um curso de graduação

A Figura 3 demonstra várias formações e agrupamentos quanto a perceber os alunos como atores conectados em forma de rede social com o uso do software e, por meio da elaboração de grafos construídos através do uso do software, evidenciar atributos estruturais e comportamentais em forma de observação empírica. De acordo com Raquel Recuero (2009, p. 24) "uma rede, assim, é uma metáfora para observar os padrões de conexão de um grupo social, a partir das conexões estabelecidas entre os diversos atores". Na figura 3, pode-se observar a estruturação da rede, contudo, sem a utilização dos filtros que compõem as métricas de análise das redes sociais, só se pode ver um aglomerado de atores sem uma visão clara do nível de envolvimento ou das atividades e dos fluxos desencadeados por cada um desses atores.

Depois de os dados serem inseridos no software, a compilação apresenta a seguinte característica: uma rede do tipo emergente, iniciada, especificamente nesse caso, por meio das interações sociais vivenciadas em sala de aula e, posteriormente, expandidas de forma emergente através de interações sociais presenciais ou em um universo virtual mediado por computador e/ou por alguma plataforma mobile. Podem-se analisar, adiante, as propriedades estruturantes dessa rede, com a utilização de métricas de ARS, tais como: grau de conexão degree; densidade - indicativo da quantidade de conexões de um grafo; centralidade - medida da popularidade de determinado nó. A popularidade desse nó ou ator é comumente associada a o quanto central ele é para uma dada rede; centralização - medida da centralização que é calculada por meio das medidas do ponto de centralidade; multiplexidade - referente às diversas qualidades e trocas que caracterizam certa conexão social. Tais métricas podem ser observadas a seguir, na figura 4.

Essa figura mostra que os alunos calouros têm menos conexões (nós menores) e se comunicam mais entre si, porque ainda não conhecem a totalidade dos veteranos. A maioria dos alunos do terceiro 
Roberto Vilmar Satur; Bruno de Araújo Ribeiro; Janecely Silveira de Lima; Guilherme Ataíde Dias

Do físico ao virtual: relações interpessoais que geram redes sociais dos alunos de um curso de graduação

semestre se conecta entre si, mas não tem muitas conexões com os demais, por isso (o tamanho dos nós) seu formato é pequeno, apesar de já estarem se aproximando dos mais veteranos. Já os alunos do quinto semestre em diante estão perfeitamente integrados com as demais turmas veteranas e demonstram grande quantidade de relações.

Figura 4 - A rede vista como pequenos agrupamentos interconectados de uma rede maior

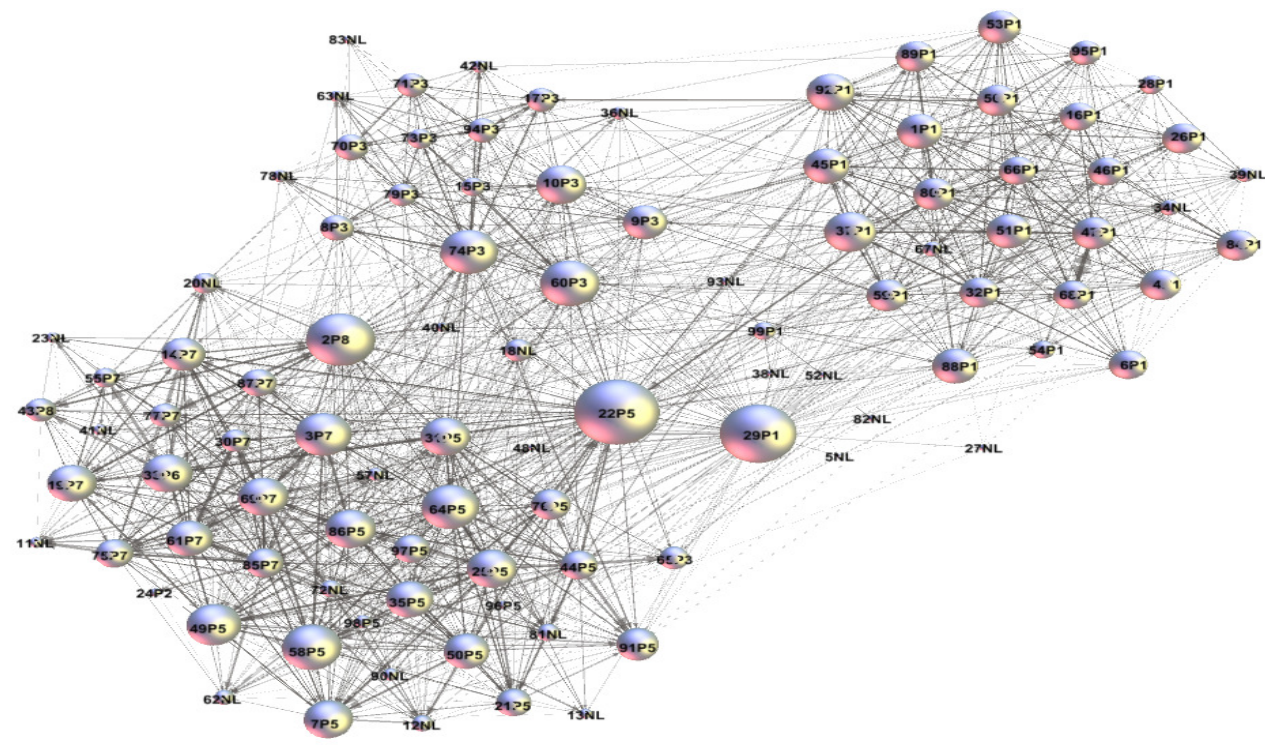

Fonte: Resultado da pesquisa (os autores)

Posteriormente, passamos a utilizar métricas e classificações com as quais pudéssemos extrair as estruturas subjacentes. Nessa distribuição, utilizamos os atributos de força de atração, repulsão e força gravitacional que incidem sobre o peso e o grau de conexões existentes entre os atores, o que revela, por meio da métrica Betweeness Centrality (Centralidade de Intermediação/Controle sobre o fluxo de informação), os atores da rede que têm um potencial controle sobre o fluxo de informação, a saber: 22P5; 29P1; 2P8; 74P3; 60P3; 10P3. Como se observa na figura 04 , aquilo que na figura 02 parecia ser uma rede densa e homogênea, revela-se uma rede social de topologia descentralizada que abriga vários centros, ou seja, a rede não é composta por um grupo uniforme de nós ou atores, mas por um grupo 
Roberto Vilmar Satur; Bruno de Araújo Ribeiro; Janecely Silveira de Lima; Guilherme Ataíde Dias

Do físico ao virtual: relações interpessoais que geram redes sociais dos alunos de um curso de graduação

de atores com atuação diferenciada. Porém um pequeno número de atores é denominado de hub's ou conectores - nós que se demonstram coesos em conexão de intermediação e que fazem a interligação com vários outros atores e seus respectivos grupos.

Outro aspecto observado na figura 04 é a formação de clusters, bem conectados e formados por grupos e laços sociais que se unem por características comuns. Nesse caso em particular, o que os une é basicamente o período letivo no qual esses nós ou atores estão inseridos - P1, P3, P5, etc. No entanto, com o passar do tempo, os atores tendem a se integrar em um grupo mais heterogêneo, no qual o período letivo deixa de ser a principal característica aglutinadora na formação desses clusters. No caso observado na Figura 04, isso fica evidente, pois percebemos que os alunos calouros têm menos conexões (nós menores) e se comunicam mais entre si, porque ainda não conhecem a totalidade dos veteranos. Já os alunos do terceiro semestre se conectam entre si, mas ainda não têm muitas conexões com os demais, portanto o tamanho dos nós fica em formato pequeno. Já os que estão no meio do curso em diante estão mais integrados, e a turma já não é mais tão evidente como requisito de comunicação, ou seja, o grupo fica ampliado para além da turma.

A Figura 5 apresenta o caso de um ator ponte (hub) que faz importantes conexões entre turmas. Como afirma Recuero (2009, p. 67), "tais redes possuiriam nós que seriam altamente conectados (hubs ou conectores) e uma grande maioria de nós com poucas conexões". 
Roberto Vilmar Satur; Bruno de Araújo Ribeiro; Janecely Silveira de Lima; Guilherme Ataíde Dias

Do físico ao virtual: relações interpessoais que geram redes sociais dos alunos de um curso de graduação

Figura 5 - Conexões de um ator ponte com forte grau de saída

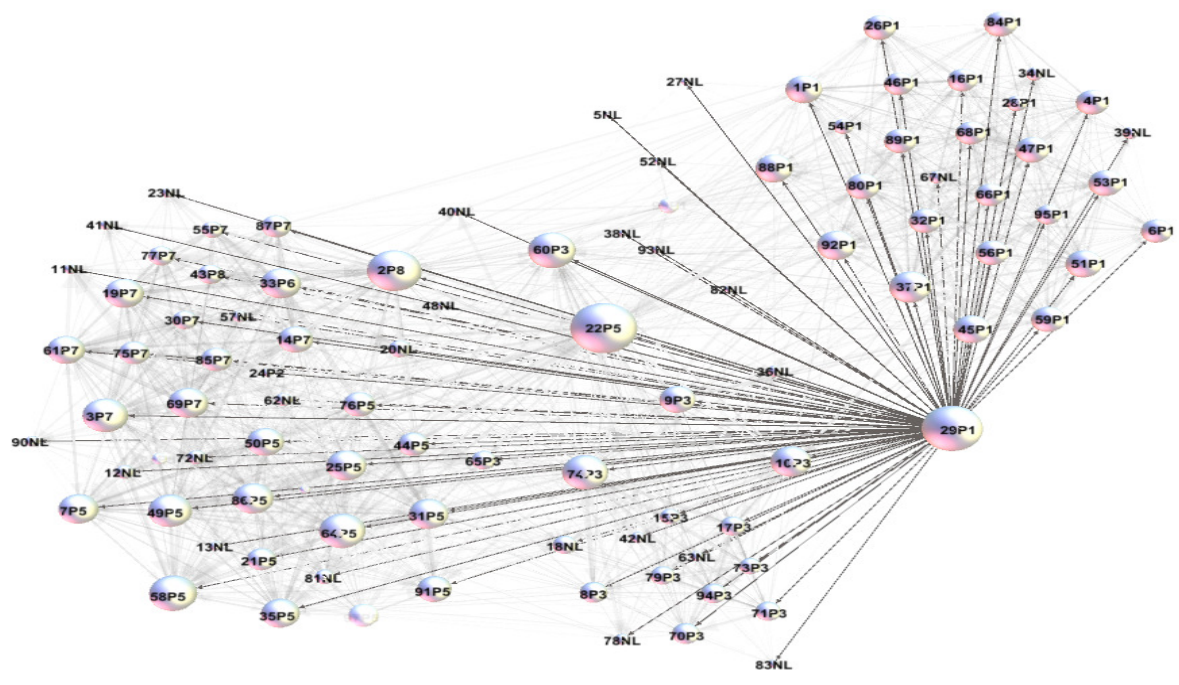

Fonte: Resultado da pesquisa (Os autores).

Como se observa na figura 05, um único ator poderá suportar uma grande quantidade de conexões, por esse motivo, assume uma posição de grande relevância na análise topológica das redes. Ao se revelar um potencial de alto grau de conexão, esse ator passa a se configurar como um hub ou ator ponte - nós que têm muito mais conexões do que os demais em determinada rede. Como afirma Grosser (1991, p. 354), o ator-ponte "é um indivíduo fortemente ligado a um [sub] grupo primário que interage regularmente com uma pessoa de outro [sub]grupo".

Deve-se, no entanto, ressaltar que, dentro de uma rede, um nó poderá ter diferentes tipos de grau de conexão, denominados de in degree (grau de entrada), que mede a quantidade de conexões recebidas, e a métrica out degree (grau de saída), que revela a quantidade de conexões que um nó emite ou inicia. Tal observação nos remete aos tipos de laços e interações que podem ser analisadas a partir dos graus de conexões mencionados - as interações do tipo mútuas e as interações reativas. 
Roberto Vilmar Satur; Bruno de Araújo Ribeiro; Janecely Silveira de Lima; Guilherme Ataíde Dias

Do físico ao virtual: relações interpessoais que geram redes sociais dos alunos de um curso de graduação

No caso do ator apresentado na figura 05, mais precisamente o nó 29P1, podemos perceber a presença dos elementos já referidos. Trata-se de um ator com um alto grau de conexão, precisamente, um alto grau de saída (Out Degree), o que, em grande medida, revela o tipo de laço e interação que esse ator exerce nos demais atores. Ou seja, uma interação reativa que é caracterizada pela limitação de laços e relações determinísticas de estímulo e resposta, o que a difere das interações mútuas, caracterizadas por relações interdependentes em que cada ator participa da construção da relação, afetando-se e interagindo mutuamente.

A Figura 06 também mostra um ator-ponte (hub) com muitas conexões. Mas, diferente do anterior, esse tem conexões recíprocas fortes, com grau de saída e de entrada.

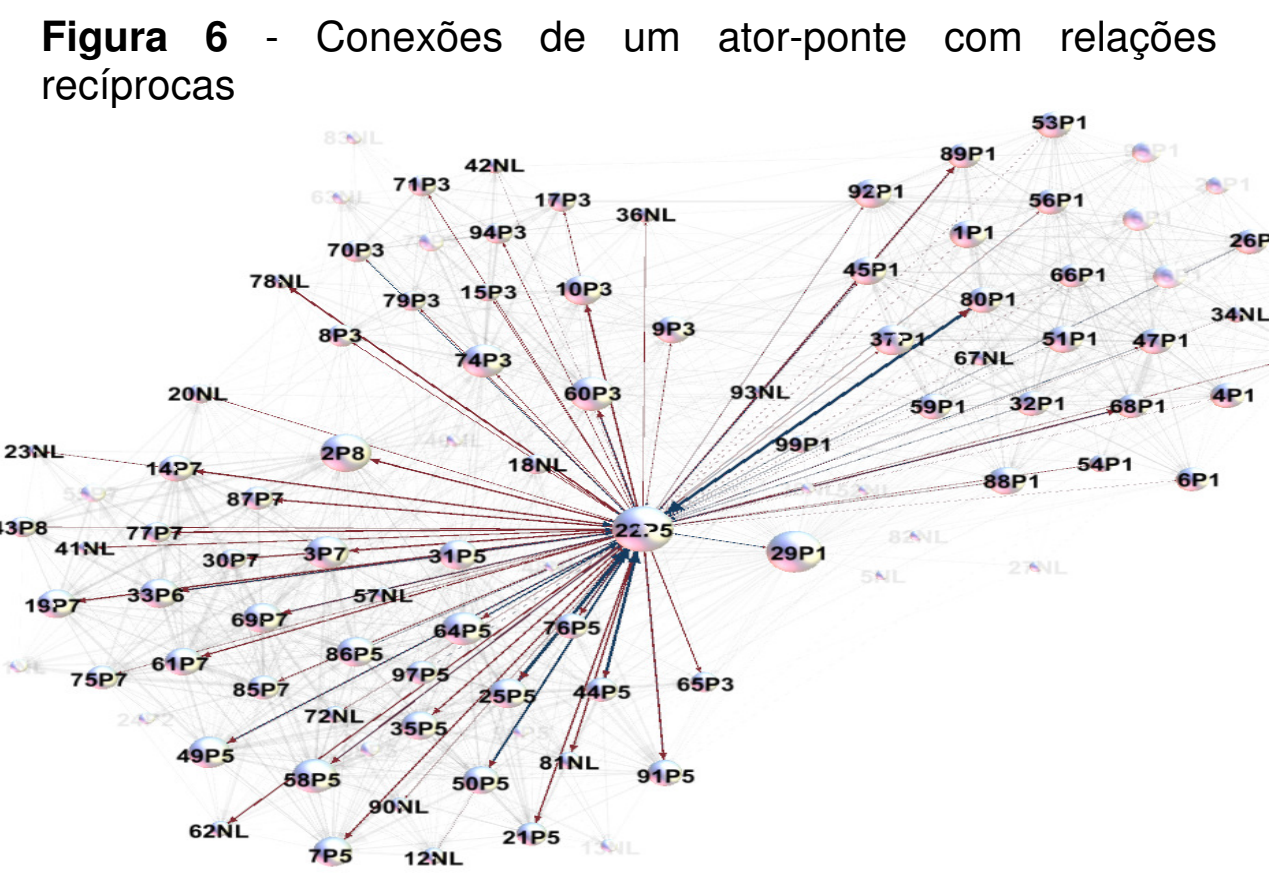

Fonte: Resultado da pesquisa (Os autores).

É o caso de um ator com interações mútuas construídas por meio de graus de conexão de entrada e de saída. Tal atribuição nos revela outro componente importante na topologia de redes, o que é 
Roberto Vilmar Satur; Bruno de Araújo Ribeiro; Janecely Silveira de Lima; Guilherme Ataíde Dias

Do físico ao virtual: relações interpessoais que geram redes sociais dos alunos de um curso de graduação

denominado de capital social. Especificamente nesse caso, um capital social relacional que é baseado nas interações entre atores. $O$ capital social é um dos elementos estudados por diversos autores como um indicativo da conexão entre pares de indivíduos em uma rede social. Também são utilizados como forma de medir a centralidade de uma rede, que é a mensuração de popularidade exercida por um nó ou ator (RECUERO, 2009). Essa popularidade está especialmente relacionada a quão central esse nó é para determinada rede e qual o seu valor constituído a partir das interações entre os demais atores em uma rede, de modo que se possa perceber sua influência e reputação. Especificamente nesse caso, o nó 22P5 revela-se como o ator de maior capital social dessa rede e que, pelo menos em relação hipotética, pode exercer forte influência nos fluxos de informação presentes nessa rede.

A identificação de um nó com alto grau de centralidade também nos fornece um elemento fundamental necessário à análise dos fluxos de interação, denominado de distância geodésica. Trata-se da medida utilizada para determinar a menor distância possível entre dois nós em uma rede. Essa distância, geralmente, é associada ao nó ou ator com maior grau de centralidade, aqui representado pelo nó 22P5. Essas interações medidas são capazes de gerar fluxos de informações e trocas sociais que impactam essas estruturas e que, consequentemente, podem alterar e/ou manter as configurações da rede.

Extraídos os principais elementos e atributos, passamos, pelo menos de forma sintética, a compreender como esse grupo se manifesta na formação da rede social e na interação com os demais atores do grupo. Além disso, observar esse fenômeno é um passo importante para se entender como a comunicação mediada por computador e/ou por uma plataforma mobile, base das principais interações nesta pesquisa, vem modificando o comportamento e as interações sociais atualmente. É válido mencionar que a formação de rede ocorre independentemente da utilização e da mediação de computador ou de outras tecnologias. Contudo, as tecnologias de comunicação e informação, como já foi dito, 
Roberto Vilmar Satur; Bruno de Araújo Ribeiro; Janecely Silveira de Lima; Guilherme Ataíde Dias

Do físico ao virtual: relações interpessoais que geram redes sociais dos alunos de um curso de graduação

oferecem oportunidades para criar ambientes ricos em fluxos de informação influenciando de modo cada vez mais dinâmico as interações interpessoais.

Apesar de esta pesquisa se restringir a um pequeno círculo acadêmico, as observações que emergem dela podem ser vistas como uma pequena amostra do que pode ser potencialmente analisado para além desse universo pesquisado. Os processos e as dinâmicas desencadeadas nas e pelas redes são decorrentes imediatas dos processos de interação e intermediação entre os atores. É interessante pensar que, apesar de sintética, esta pesquisa demonstra os principais mecanismos que regem as mediações, as interações, os ordenamentos, as cooptações e as desmembrações que formam, caracterizam e mantêm as redes sociais, tendo em vista que todas elas podem ser encontradas e observadas em outras realidades locais ou em qualquer parte do mundo, estejam ou não mediadas por tecnologias de informação e comunicação.

Nesse sentido, estudar os fenômenos que possam traduzir esse novo comportamento e essas novas interações sempre é de fundamental importância, considerando o processo irreversível de virtualização social. Nesse cenário, os instrumentos de caráter tecnológico passam a figurar como ferramentas cada vez mais importantes no processo de ensino-aprendizagem, pois podem estar relacionados ao progresso de competências, habilidades e atitudes que promovam o aproveitamento de todas as tecnologias, objetivando construir um elo entre os professores, a internet, os alunos, a Academia, as ações e as políticas pedagógicas.

A Figura 06 também mostra um ator-ponte (hub) com muitas conexões, mas diferente do anterior, porque tem conexões recíprocas fortes, com grau de saída e de entrada. Como afirma Grosser (1991, p. 354), o ator-ponte "é um indivíduo fortemente ligado a um [sub] grupo primário que interage regularmente com uma pessoa de outro [sub]grupo". As implicações disso serão discutidas no capítulo seguinte. 
Roberto Vilmar Satur; Bruno de Araújo Ribeiro; Janecely Silveira de Lima; Guilherme Ataíde Dias

Do físico ao virtual: relações interpessoais que geram redes sociais dos alunos de um curso de graduação

Figura 7 - Conexões da rede com ênfase nos atores-ponte com o maior capital social

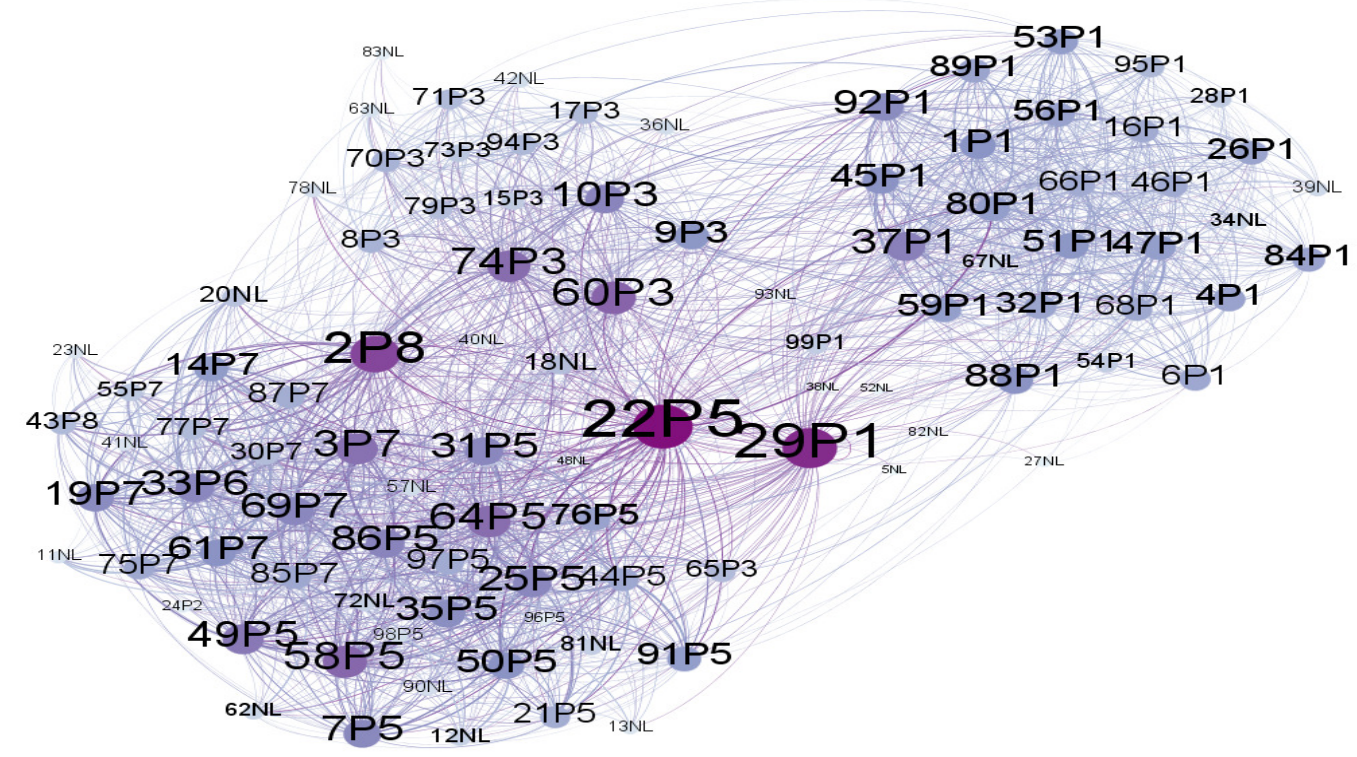

Fonte: Resultado da pesquisa (Os autores).

A Figura 07 enfatiza a rede distribuída e seu contexto levando em conta a situação de cada ator. Nela é possível visualizar o capital social de cada ator pela quantidade de conexões e o peso delas. Vê-se, por exemplo, que os atores que têm muitas conexões com reciprocidade aparecem mais no centro da rede (por exemplo: 22P5, 2P8, 74P3, 60P3), enquanto um ator muito conectado, mas sem tanta reciprocidade (mais emite que recebe), embora fique em posição de destaque, não fica tão ao centro (por exemplo: 29P1). A maioria de outros que são lembrados, de certa forma, pelos atores, mas que não se registrou sua reciprocidade para os demais atores ficou na parte externa da rede (os com finais $\mathrm{NL}$ ).

Por fim, apresentam-se os dados estatísticos básicos gerados pelo software Gephi sobre esta pesquisa. 
Roberto Vilmar Satur; Bruno de Araújo Ribeiro; Janecely Silveira de Lima; Guilherme Ataíde Dias

Do físico ao virtual: relações interpessoais que geram redes sociais dos alunos de um curso de graduação

Figura 8 - Dados estatísticos da pesquisa desenvolvida

\begin{tabular}{|c|c|c|c|}
\hline \multicolumn{4}{|l|}{ — Visão Geral da Rede } \\
\hline Grau médio & 20,01 & Executar & (2) \\
\hline Grau ponderado médio & 48,545 & Executar & (2) \\
\hline Diâmetro da rede & 4 & Executar & (2) \\
\hline Densidade do grafo & 0,204 & Executar & (2) \\
\hline HITS & & Executar & (2) \\
\hline Modularidade & 0,391 & Executar & (2) \\
\hline PageRank & & Executar & (2) \\
\hline Componentes conectados & 1 & Executar & (2) \\
\hline \multicolumn{4}{|l|}{$\checkmark$ Visão geral dos nós } \\
\hline Coeficiente de clustering médio & 0,489 & Executar & (2) \\
\hline Centralidade de autovetor & & Executar & (2) \\
\hline \multicolumn{4}{|l|}{ ๑ Visão geral das arestas } \\
\hline Comprimento médio de caminho & 1,822 & Executar & (2) \\
\hline
\end{tabular}

Fonte: Resultado da pesquisa no Software Gephi (Os autores).

A Figura 8 mostra os dados gerais dos grafos e da rede gerada por esse estudo. Pode-se destacar, por exemplo, que, para um ator, basta outro ator para conseguir chegar a qualquer ator da rede, o que caracterizaria a rede como "mundo pequeno". Convém destacar que a rede gerou grau médio de 20,01, grau ponderado médio de 48,545, densidade do grafo 0,204 , coeficiente de clustering médio de 0,489 e comprimento médio do caminho de 1,822.

\subsection{Limitações da Pesquisa}

O estudo realizado apresentou algumas limitações referentes à amostra e aos sujeitos envolvidos na pesquisa, nesse caso, os alunos do Curso de Letras Estrangeiras Aplicadas às Negociações Internacionais da UFPB, listados no final do mês de maio de 2014, que não foram totalmente encontrados, porquanto 0 calendário da universidade ainda estava atrasado em decorrência das greves dos anos anteriores, e junho era o período de trancamento ou cancelamento de matrícula. Logo, alguns alunos trancaram ou cancelaram sua 
Roberto Vilmar Satur; Bruno de Araújo Ribeiro; Janecely Silveira de Lima; Guilherme Ataíde Dias

Do físico ao virtual: relações interpessoais que geram redes sociais dos alunos de um curso de graduação

matrícula nesse período, e outros desistiram de frequentar a aula, o que significa que seriam reprovados por falta. Outros sequer devolveram o questionário respondido. Mesmo assim, o resultado conseguido foi interessante, porquanto houve o retorno de 71 (setenta e um) questionários, praticamente a totalidade dos alunos que continuavam frequentando o semestre no final de junho.

Em relação à coleta dos dados, consideramos a confiabilidade dos dados obtidos, visto que todos foram contabilizados minuciosamente e compilados primeiramente em planilha eletrônica adequada e, depois, pelo software GEPHI, para a elaboração de grafos, estudos e ilustrações.

\section{CONSIDERAÇÕES FINAIS}

Nesta pesquisa, consideraram-se as redes sociais como um espaço de comunicação e interação entre humanos, com uso cada vez mais intenso de tecnologias e artefatos. O estudo mostrou, ainda, que as redes sociais virtuais podem ter um papel importante na educação, contribuindo para o processo de ensino e aprendizagem, com avanços nas formas de interação, acesso, busca e compartilhamento de informações entre os seus usuários. As redes sociais tradicionais (por exemplo, as salas de aula física) se recriam e se prolongam virtualmente como uma extensão do ambiente físico e, as vezes, confundindo-se com ele.

Assim, extraídos os principais elementos e atributos pode-se, pelo menos de forma sintética, compreender como esse grupo de alunos pesquisado se manifesta na formação da rede social e na interação com os demais atores do grupo. Há que se ressaltar que observar esse fenômeno é um passo importante para se entender como a comunicação mediada por computador e/ou por uma plataforma mobile, base das principais interações, vem modificando o comportamento e as interações sociais na atualidade. A formação de rede ocorre 
Roberto Vilmar Satur; Bruno de Araújo Ribeiro; Janecely Silveira de Lima; Guilherme Ataíde Dias

Do físico ao virtual: relações interpessoais que geram redes sociais dos alunos de um curso de graduação

independentemente da utilização e da mediação por computador ou outras tecnologias, contudo, as tecnologias digitais, de informação e comunicação, como já mencionadas, oferecem oportunidades para se criarem ambientes ricos em informação, que podem influenciar, de modo cada vez mais dinâmico, as interações interpessoais.

Estudar os fenômenos que possam traduzir esse novo comportamento em rede e essas novas interações sociais é de fundamental importância e poderá contribuir com os ganhos de aprendizagem, inclusive pedagógicos. Essa é uma forma de auxiliar os educandários e os educandos a entenderem esse ambiente e atuarem com mais competência neles, tendo em vista que tal processo de virtualização das redes parece ser algo irreversível.

Assim, os instrumentos de caráter tecnológico passam a figurar como ferramentas cada vez mais importantes no processo de ensinoaprendizagem e estão relacionados ao progresso de competências, habilidades e atitudes que poderão promover o aproveitamento de todas as tecnologias, com o objetivo de criar um elo entre os professores, a internet, os alunos, a Academia, as ações e as políticas pedagógicas. Nesse contexto, não podemos nos eximir de compreender a importância dessas redes na organização social contemporânea, seus novos valores, seus fluxos emergentes de informação e as interações e as mobilizações que já se confundem, em parte, com o real e o virtual.

No caso específico apresentado nas ilustrações e nos dados da pesquisa deste artigo, constatou-se que as turmas dos primeiros semestres levam certo tempo para se integrar plenamente no curso através da interação em rede. Assim seria relevante, para casos como esses, a coordenação, os professores e as lideranças estudantis dos cursos em geral que apresentem essa característica fazerem trabalhos e eventos no início de cada ano letivo, quando ingressam turmas novas,, para que se integrem mais rapidamente com os demais alunos e as turmas e possam, desde o início do curso, interagir e compartilhar dele plenamente pela rede social física e virtual. Assim, será possível gerar, o 
Roberto Vilmar Satur; Bruno de Araújo Ribeiro; Janecely Silveira de Lima; Guilherme Ataíde Dias

Do físico ao virtual: relações interpessoais que geram redes sociais dos alunos de um curso de graduação

mais rápido possível, uma rede mais integrada como a da figura 4, que envolvia os alunos veteranos, e estender essa interação para todos os demais alunos. Pedagogicamente, amplia-se a possibilidade de haver ganhos entre os alunos decorrentes dessas trocas mútuas. Assim, o curso cresce em unidade e em rede mais consolidada.

\section{AGRADECIMENTOS}

Nossos agradecimentos aos estudantes LEA da UFPB, por terem colaborado respondendo à pesquisa, e ao PPGCI da UFPB, que oportuniza estudos como este sobre redes sociais.

\section{REFERÊNCIAS}

ALBERT, Réka; BARBÁSI, Albert-László. Statistical mechanics of complex networks. Reviews of Modern Physics, Minneapolis, v. 74, p. 47-97, Jan. 2002.

AMARAL, Caroline Bohrer; BEHAR, Patricia Alejandra; DORNELLES, Leni Vieira. Ciberinfância: um desafio para os planejamentos pedagógicos. Revista Novas Tecnologias na Educação da Universidade Federal do Rio Grande do Sul, Porto Alegre, v. 9, n. 1, jul. 2011. Disponível em:

<http://seer.ufrgs.br/index.php/renote/article/view/21918/12718>. Acesso em: 5 jan. 2015.

BARABÁSI, Albert-László. Network science. 2012. Disponível em: $<$ http://barabasilab.neu.edu/networksciencebook/downIPDF.html>. Acesso em: 5 jan. 2015.

BARABÁSI, Albert-László; BONABEAU, Erick. Scale-free network. Science American, Canadá, p. 50-59, May 2003. Disponível em: <http://barabasilab.neu.edu/networksciencebook/downIPDF.html>. Acesso em: 6 Jan. 2015. 
Roberto Vilmar Satur; Bruno de Araújo Ribeiro; Janecely Silveira de Lima; Guilherme Ataíde Dias

Do físico ao virtual: relações interpessoais que geram redes sociais dos alunos de um curso de graduação

BASTIAN, Mathieu; HEYMANN, Sebastien; JACOMY, Mathieu. Gephi: an open source software for exploring and manipulating networks.

Disponível em: <https://gephi.org/publications/gephi-bastian-feb09.pdf>. Acesso em: 5 jun. 2014.

SCLARA, Maria. Análise e visualização de redes: o GEPHI. 2013.

Disponível em: <http://humanidadesdigitais.org/2013/08/16/analise-evisualizacao-de-redes-o-gephi/>. Acesso em: 9 jun. 2014.

GRANOVETTER, Mark S. The estrength of wiek ties. American Journal of Sociology, Chicago, v. 78, n. 6, p. 1360-1380, May 1973.

GROSSER, Kerry. Human network in organizational information processing. Annual Review of Information Science and Technology, New Jersey, v. 26, p. 349-402, 1991.

KLEN, Otávio José. A gênese do conceito de dispositivo e sua utilização nos estudos midiáticos. Revista Estudos em Comunicação, Covilhã, n. 1, p. 215-231, abr. 2007.

MATHEUS, Renato Fabiano; SILVA, Antonio Braz de Oliveira.

Fundamentação básica para a análise de redes sociais: conceitos, metodologia e modelagem matemática. In: POBLACIÓN, Dinah Aguiar (Org.). Redes sociais e colaborativas em informação científica. São Paulo: Angellarra, 2009. p. 239-287.

PINHEIRO, Marcus Túlio Freitas. O conhecimento enquanto campo: 0 ente cognitivo e a emergência de conceitos. 2012. Tese (Doutorado em Educação) - Universidade Federal da Bahia, Salvador, 2012.

PRODANOV, Cleber Cristiano; FREITAS, Ernani Cesar. Metodologia do trabalho científico: métodos e técnicas da pesquisa e do trabalho acadêmico. 2. ed. Novo Hamburgo: Universidade Feevale, 2013.

RECUERO, Raquel. Redes sociais na internet. Porto Alegre: Sulina, 2009.

SIEMENS, George. New structures and spaces of learning: the systemic impact of connective knowledge, connectivism, and networked learning. 2011. Disponível em:

<http://elearnspace.org/Articles/systemic_impact.htm>. Acesso em: 9 jul. 2014.

TSWETOVAT, M.; KOUZNETOV, A. Social network analysis for startups. Sebastopol, CA, (EUA): O’Reilly Media, Inc., 2011.

WASSERMAN, Stanley; FAUST, Katherine. Social network analysis: methods and applications. Cambridge: University Press, 1994. 
Roberto Vilmar Satur; Bruno de Araújo Ribeiro; Janecely Silveira de Lima; Guilherme Ataíde Dias

Do físico ao virtual: relações interpessoais que geram redes sociais dos alunos de um curso de graduação

\section{Title}

From physical to virtual: interpersonal relations generating networks among students of a graduate course

\section{Abstract}

Introduction: Nowadays, the social networks are more present in people's daily lives, especially students, becoming a reality in the educational environment. More than entertainment, these networks have been a valuable interaction tools to passing information through.

Objective: In this scenario, the aim of this research is to observe the interpersonal and intragroup interaction abilities in a group of undergraduate students in a public university in order to understand the formation and expansion of social networks initiated through personal contact and extended to the virtual universe. In that sense, it aims specifically at mapping the students interpersonal interactions in the creation of social networks and the expansion of their relations. It describes which are the most used forms of interaction and it gets a basic profile data of the actors.

Methodology: To better understand the reality of these subjects it has been adopted as an instrument of data collection, a questionnaire consisting of closed questions directed to students of the course mentioned. A total of 95 student names were enrolled in the course in last May, who could be marked by the respondents. The survey was carried out throughout June 2014 and tallied 71 answered questionnaires. After the data collection, the data were tabulate and it was applied the Gephi software.

Results: The results show a tendency to form an extensive network within the course, but it is more intense among certain students, forming small groups and the existence of actors-bridge. The article also showed that there was a clear transposition from the personal relationship contact to the virtual environment.

Conclusion: Social networks can increasingly serve as a space for communication and interaction, although the use of these networks in education is related to the teaching and learning process, making advances in the ways of interaction and access to information and search among its users. Therefore, to study these phenomena that might be translated on new behavior and these new interactions are fundamentally important, taking into account the process to some extent irreversible of social virtualization.

Keywords: Social networks. Interpersonal relations. LEA Students. GEPHI.

\section{Titulo}

De físico a virtual: relaciones interpersonales que generan redes sociales entre los estudiantes universitarios

\section{Resumen}


Roberto Vilmar Satur; Bruno de Araújo Ribeiro; Janecely Silveira de Lima; Guilherme Ataíde Dias

Do físico ao virtual: relações interpessoais que geram redes sociais dos alunos de um curso de graduação

Introducción: Hoy en día, las redes sociales han causado una gran participación en la vida cotidiana de la gente, especialmente a los estudiantes, convirtiéndose en una realidad en el ámbito educativo. Más de entretenimiento, la red ha sido la interacción valiosa para ayudar en las herramientas de informes.

Objetivo: El objetivo de essa investigación es observar la capacidad de las interacciones interpersonales y dentro del grupo de estudiantes en un curso de postgrado (Lenguas Extranjeras Aplicadas en Negociaciones Internacionales), una universidad pública (UFPB), la formación y expansión de redes sociales iniciadas a través personal y extenderse al mundo virtual de contactos. En esse sentido, tiene como objetivo mapear específicamente las interacciones interpersonales de los estudiantes en la formación de las redes sociales y la ampliación de sus relaciones; describirá las formas de interacción de datos básicos más utilizados y elevar el perfil de los jugadores.

Métodos: Para entender mejor la realidad de estos temas, ha sido adoptado como un instrumento de recolección de datos, un cuestionario con preguntas cerradas, dirigidas a los estudiantes del curso mencionado. En total, 95 nombres de los estudiantes fueron enlistadas en el curso en mayo, lo que podría ser marcado por los encuestados. La encuesta se realizó durante el mes de Junio de 2014 y 71 cuestionarios contados. Después de la recogida, los datos fueron puestos en libertad y se aplican al software Gephi.

Resultados: Los resultados muestran la tendencia a la formación de una extensa red en el curso, pero más intensa entre ciertos estudiantes forman grupos reducidos y la existencia de actores-puente. El artículo también mostró que no había un cambio claro de la persona enlace de contacto para el entorno virtual.

Conclusiones: A pesar de que las redes sociales pueden servir aún más espacio para la comunicación y la interacción, ya que el uso de éstos en la educación está relacionada con el proceso de enseñanza y aprendizaje, con los avances en las formas de interacción y acceso a la información y la búsqueda entre sus usuarios. Por lo tanto, el estudio de los fenómenos que podrían traducir essa nueva conducta y essas nuevas interacciones es de fundamental importancia, en vista del proceso en cierta medida irreversible virtualización social.

Palabras clave: Redes sociales. Relaciones interpersonales. Estudiantes de LEA. Gephi.

Recebido em: 23/09/2014

Aceito em: $14 / 05 / 2015$ 